\title{
AMULETOS Y TALISMANES EN EL RETRATO DEL PRÍNCIPE FELIPE PRÓSPERO DE VELÁZQUEZ
}

\author{
POR \\ NATALIA HORCAJO PALOMERO \\ Dra. por la Universidad Complutense de Madrid
}

This article, in memoriam to the late teacher D. Jesús Hernández Parera, aims to study some magic jewels in the portrait of Prince Felipe Próspero by Velázquez, jewels which were believed to posses medical properties against the «mal de ojo». These jewels are the «higa» and the «campanilla» and were wed by the royal family for some centuries in Spain, and can also be found in some portraits of children.

A la memoria de D. Jesús Hernángdez Perera

En 1960 publicó D. Jesús Hernández Perera un estudio insólito sobre Velázquez, insólito, porque trató un aspecto de la pintura del genial sevillano que nunca antes había sido estudiado, las joyas que aparecen representadas en sus cuadros ${ }^{1}$. En el artículo, muy trabajado e interesante, el profesor analizaba todas las piezas de joyería que llevaban los hombres, las mujeres y los niños inmortalizados por el pintor, en su mayoría miembros de la Familia Real, acudiendo, cuando lo creía necesario, y era posible, a las fuentes documentales, en busca de datos sobre aquellas alhajas, y señalando la importancia que estas podían tener a la hora de datar una pintura, contribuyendo con ello a revalorizar su estudio, el estudio de una manifestación artística considerada tradicionalmente como «Arte Menor».

Ciertamente poco puede añadirse a tan magnífico trabajo, pero me van a permitir que partiendo de él, y en concreto de las joyas de un niño, el Príncipe Felipe Próspero, estudiemos el empleo de ciertos amuletos y talismanes, que ya se venían usando por la Familia Real española desde el siglo XVI, y que aparecen en varios retratos de Infantes.

Antes de nada creo oportuno establecer las diferencias que existen entre un amuleto y un talismán, porque aunque todos sabemos que ambos tienen que ver con los poderes ocultos y la magia, y que se los usaba buscando protección frente a peligros o enfermedades, lo cierto es que no son lo mismo. El amuleto, es la materia con la que se hace un objeto y le hace adquirir por ello su valor mágico, mientras que en el talismán, es la forma que le damos a ese objeto lo que le convierte en mágico. Por poner un ejemplo muy sencillo y del mundo de la joyería, la esmeralda sería un amuleto, porque se consideraba que servía, entre otros usos, 286.

1 Hernández Perera, Jesús: «Velázquez y las joyas». Archivo Español de Arte, n. XXXIII (1960), pp. 251 - 
para hacer guardar la castidad y ahuyentar las tempestades ${ }^{2}$, mientras que una joya en forma de ojo se relacionaba con el «ojo de Dios que todo lo ve» y se utilizaba para protegerse de las influencias del demonio ${ }^{3}$.

Cuando Velázquez pinta al Príncipe Felipe Próspero en 1659, (Kunsthistorisches Museum, Viena), (Fig. 1), el desdichado niño, que entonces contaba dos años y que fallecería poco tiempo después, se nos muestra cargado de amuletos y talismanes, lo que aún pone más de manifiesto su desvalimiento. Felipe IV no tenía suerte con sus hijos varones, todos ellos eran enfermizos y le habían hecho abrigar, con la excepción del Príncipe Baltasar Carlos, pocas esperanzas sobre su sucesión. Quizás por esta razón, se buscaba tan ansiosamente la protección del «Más Alláa, y se le colgaban a los pequeños príncipes aquellos «objetos de virtud» que iban heredando a la muerte de sus hermanos mayores y cuyo uso, tanto en adultos como en niños, podía ser localizado en parientes no lejanos.

De todos los que nos muestra Felipe Próspero, por su relación con otros anteriores llevados por infantes de la Casa de Austria, he seleccionado dos de gran importancia, una higa de azabache y una campanilla de oro.

En el caso del primero, estamos ante un objeto muy peculiar, ya que en él se aunan las características del amuleto con las del talismán, por lo que podemos deducir que su protección había de ser considerada doblemente eficaz. El amuleto, como ya se habrá comprendido es el azabache, mientras el talismán, es la higa. Entre las facultades que se le atribuían al azabache, una variedad del lignito, estaba el proteger a los niños del mal de ojo ${ }^{4}$. La higa, una pequeña mano con el puño cerrado, dejando asomar el dedo pulgar entre los dedos índice y corazón, era considerada como un profiláctico que actuaba igualmente contra el mal de ojo ${ }^{5}$.

La creencia en el aojamiento o mal de ojo, estaba muy extendida por todo el Mediterráneo, con raices en la cultura egipcia. Aojar según el Diccionario de Autoridades consistía en «Hacer mal de ojo, dañar a otro con la vista, por haber en ella infección, que se comunica con los rayos visuales, o por mirar con ahínco a causa de envidia, admiración, y a veces cariño» ${ }^{6}$. Aunque nadie estaba libre de escaparse, los niños se consideraba que eran las víctimas más propicias a este tipo de hechizos.

En cuanto a la campanilla de oro, servía para ahuyentar a los malos espíritus con su sonido, y más concretamente, para ahuyentar brujas, como me indicó, en cierta ocasión, personalmente D. Jesús. Se trata por lo tanto de un talismán, ya que las propiedades que se le atribuían al oro, conformar la flaqueza del corazón, conferir alegría y magnanimidad y quitar la melancolía ${ }^{7}$, no parecen tener ninguna relación con lo anteriormente expuesto.

Ahuyentar brujas y evitar el aojamiento, estos eran sin duda los propósitos que llevaron a Felipe IV y a su esposa Mariana a tomar la decisión de seguir con la costumbre, ya familiar, de cubrir a su hijo de amuletos y talismanes.

2 Morales, Gaspar De: De las virtudes y propiedades maravillosas de las piedras preciosas. Madrid, Editora Nacional, 1977, pp. 229-234.

3 Hackenbroch, Yvonne: Renaissance Jewellery, Londres, Sotheby Parke Bernet Publications, 1979, pp. 23-24.

4 Morales, Gaspar de: Op. Cit., p. 342.

5 Robinson, J. C.: Catalogue of the special loan exhibition of Spanish and Portuguese ornamental Art. Londres, Chapman \& Hall, 1881, p. 73, n. ${ }^{\circ} 301$.

6 Rey Bueno, Mar: El Hechizado. Medicina, alquimia y superstición en la Corte de Carlos II. 1661-1700. Madrid, Ediciones Corona Borealis, 1998, p. 30.

7 Arfe y Villafañe, Juan: Quilatador de la plata, oro y piedras, 1572. Madrid, Ministerio de Educación y Ciencia, 1975, p. 23. 
La mortalidad infantil entre los hijos de los Austrias era elevadísima. También son numerosas las causas que pueden explicar, desde un punto de vista científico, estas altas tasas de mortalidad: La endogamia matrimonial con su correspondiente consanguinidad, la juventud excesiva de las Reinas, sus embarazos continuos, la mala atención en el parto, tanto por los médicos como por las comadronas, la sífilis que padecían los Reyes y que contagiaban a sus cónyuges, y ya concretamente en los bebés recién nacidos, la mala elección de nodrizas y su continuo cambio.

Felipe IV bien podía presumir de paternidad, se le atribuyen más de treinta hijos naturales, pero en el caso de los legítimos, catorce, cuatro varones y díez hembras, sólo tres llegaron a la edad adulta, las Infantas María Teresa y Margarita, las dos ligadas a Velázquez, la primera, porque fue con motivo de los preparativos de su enlace, que el pintor enfermara y falleciese, y la segunda, por su indiscutible protagonismo en varios retratos y en especial en «Las Meninas», y el Príncipe y heredero, Carlos, de cuya salud enfermiza y debilidad absoluta no hay discusión posible.

Los hijos de Felipe, tanto con su primera mujer, Isabel de Borbón, como con la segunda, Mariana de Austria, ocho con aquélla y seiś con ésta, fallecieron, en su mayoría, a las horas o días de nacer, y de los que sobrevivieron un tiempo, como el caso del Príncipe Felipe Próspero, nacido en 1657 y fallecido en 1661, siempre padeció de alferecía, es decir de epilepsia, mal que le llevó a la tumba como había hecho con su hermana María Ambrosia de la Concepción, a las pocas semanas de su nacimiento en 1655. Sólo pareció que escapaba a esta maldición el Príncipe Baltasar Carlos (1629-1646), igualmente inmortalizado por Velázquez en varios retratos, ya que parece gozar en ellos de buena salud, para felicidad del Rey, felicidad que se vió truncada por un mal muy extendido en la época, la viruela, que açábó con el heredero según su padre «rendido en cuatro días de la más violenta enfermedad que dicen los médicos han visto nunca» ${ }^{8}$.

En una monarquía hereditaria, es fundamental el papel del heredero, de ahí el miedo que tuvieron que pasar los Austrias al ver morir uno tras otro a sus hijos, y con ellos desaparecer toda esperanza de sucesión, hecho que finalmente daría fin a su Dinastía, cuando Carlos II moría sin descendientes y los Borbones accedían al trono de España.

Mas, ¿cómo explicarse que, en una monarquía tan católica como fue la española de los siglos XVI y XVII, los propios Reyes se aventurasen en este mundo de supersticiones haciéndose partícipes de ellas, y al hablar de Reyes no sólo me estoy refiriendo a Felipe IV y sus dos esposas, sino también al catolicísimo Felipe II, que nos ha dejado un retrato de uno de sus hijos, Diego Félix, «protegido»?

La respuesta es más sencilla de lo que uno se piensa, no se cometía ningún tipo de pecado por utilizar amuletos y talismanes, el propio Niño Jesús los lleva en numerosos cuadros de la época, como la rama de coral, que pendiente de una sarta, le cuelga del cuello en el Retablo de Brera (Galeria Brera, Milán), pintado alrededor de 1472-1474, por Piero della Francesca, y además, su uso estaba incluso recomendado por los propios médicos. El doctor Juan Alonso de los Ruyzes de Fontecha, en su obra Diez privilegios para mugeres preñadas, publicada en Alcalá de Henares en $1606^{\circ}$, en el privilegio dezimo declara «que puede la preñada prevenirse de cosas para que no le aojen su criatura en naziendo, si ay ojo, de quantas maneras aconteze, que señales ay para conozelle, como se cura y con que remedios

${ }^{8}$ Junceda Avello, Enrique: Ginecología y vida íntima de las Reinas de España. De Isabel La Católica a la Casa de Borbón. Madrid, Ediciones Temas de Hoy, 1995, p. 189.

${ }^{9}$ Alonso de los Ruyzes y Fontecha, Juan: Diez previlegios para mugeres preñadas. Alcalá de Henares, Luis Martínez Grande, 1606, índice y folio 177 y ss. 
se prohibe y sana». Tras este enunciado, el doctor pone de manifiesto toda su erudición al servicio de la «fastinatio» (fascinación) o aojo, citando textos clásicos (Plinio, Galeno, Aristóteles...), en latín, para tratar de explicar científicamente en qué consiste, a la vez que busca remedios contra él. Las conclusiones a las que llega se identifican con la definición de aojar a la que he hecho alusión anteriormente, y como solución apunta el uso del azabache, bendiciendo a Dios porque «que ya que al pobre le falte el pedaço honrrador y desmelancoliçador del Oro, Saphiro, Esmeralda, Iacinto y Diamante, para colgar al cuello de su hijo por sus grandes precios y estimaciones, no le faltará un negro pedaço de azabache aunque sea de los que se quiebran en casa de los ricos, para contra la maligna qualidad de los fascinadores, o unos granos de fino coral, pues no ay pobre labradora que no tenga sus sarticas del qual no menores alabanças y grandezas, según nuestro propósito han dicho los antiguos, que de essotras preciosas piedras y del azabache como queda explicado», y más adelante afirma: "Y si aun todavía se afligiere el pobre que no tiene un poco de azabache o coral que echar al cuello de su único hijo, consuelele con que podrá echalle un pedaço de sal cuajada y hazelle una cruz, coraçon o higa, que no parecerá menos bien...» ${ }^{10}$.

Estos testimonios sirven para que tomemos conciencia de cual era la mentalidad religiosa y «científica» en la que se movieron los Austrias, aunque esta mentalidad también contó con sus detractores, como Pedro Ciruelo, quien ya en 1534 en su obra Reprobación de las supersticiones y hechicerías, en el capítulo V criticaba «los aojamientos y otros maleficios ${ }_{1}^{11}$.

Estas creencias en favores sobrenaturales de piedras y objetos ya se encuentran en la persona de Carlos I, quien utilizó las turquesas engastadas en sortijas, para protegerse de las caídas del caballo ${ }^{12}$. Felipe II, su hijo, también poseyó algunas de estas «maravillas» y fue él, junto con su cuarta y última esposa, Ana de Austria, quien inaguró, al parecer, la costumbre de proteger a sus hijos con ellas, aunque se conserva en Simancas un documento que cita una higa de coral guarneçida de oro, propiedad de Isabel de Valois, guardada por la Infanta Isabel Clara Eugenia ${ }^{13}$. Sin embargo, el primer retrato de un «Infante protegido» que he podido localizar, es el ya aludido del pequeño Diego Félix, nacido en 1575 y fallecido a causa de la viruela en 1582. La pintura, (en una colección particular), de Sánchez Coello, datada en 1577, (Fig. 2), cuando el niño tenía dos años, nos lo muestra con un aspecto no muy saludable, lo que nos hace pensar que sería de naturaleza enfermiza, y que falleció de viruela como podía haber fallecido de cualquier otra enfermedad. Sin embargo, sus joyas, nos dan una pista: Entre ellas, destaca un colgante con un coral en forma de corazón, engastado en oro. El corazón era considerado un talismán que servía para proteger la vida, mientras, al coral, como amuleto, se le atribuían propiedades medicinales: Curaba las enfermedades del estómago, especialmente las náuseas y los vómitos, el intestino y el hígado, cortaba las hemorragias y era bueno para el corazón ${ }^{14}$, como igualmente lo era el oro, según ya se ha indicado. Está bastante claro, que la dolencia de Diego Félix tenía que

10 Ibidem, folios $224 \mathrm{R}$ y $225 \mathrm{R}$.

11 Ciruelo, Pedro: Reprobación de las supersticiones y hechicerías. Barcelona, Editorial Glosa, 1977, pp. 119-122.

12 Horcajo Palomero, Natalia: «Carlos I y los amuletos de turquesas». Goya, n. ${ }^{\circ} 138$ (1977), pp. 350 353.

13 «Archivo General de Simancas» (AGS). Casa y Sitios Reales. Legajo 80. 1568. «Cargo y data de Cristobal de Oviedo, guardajoyas de la Reina D. ${ }^{a}$ Isabel de Valois de los bienes, alhajas, tapicerías y demás efectos de su magestad que se depositaron en él para hacer almoneda de ellos».

14 Morales, Gaspar de: Op. Cit., pp. 296-307. 


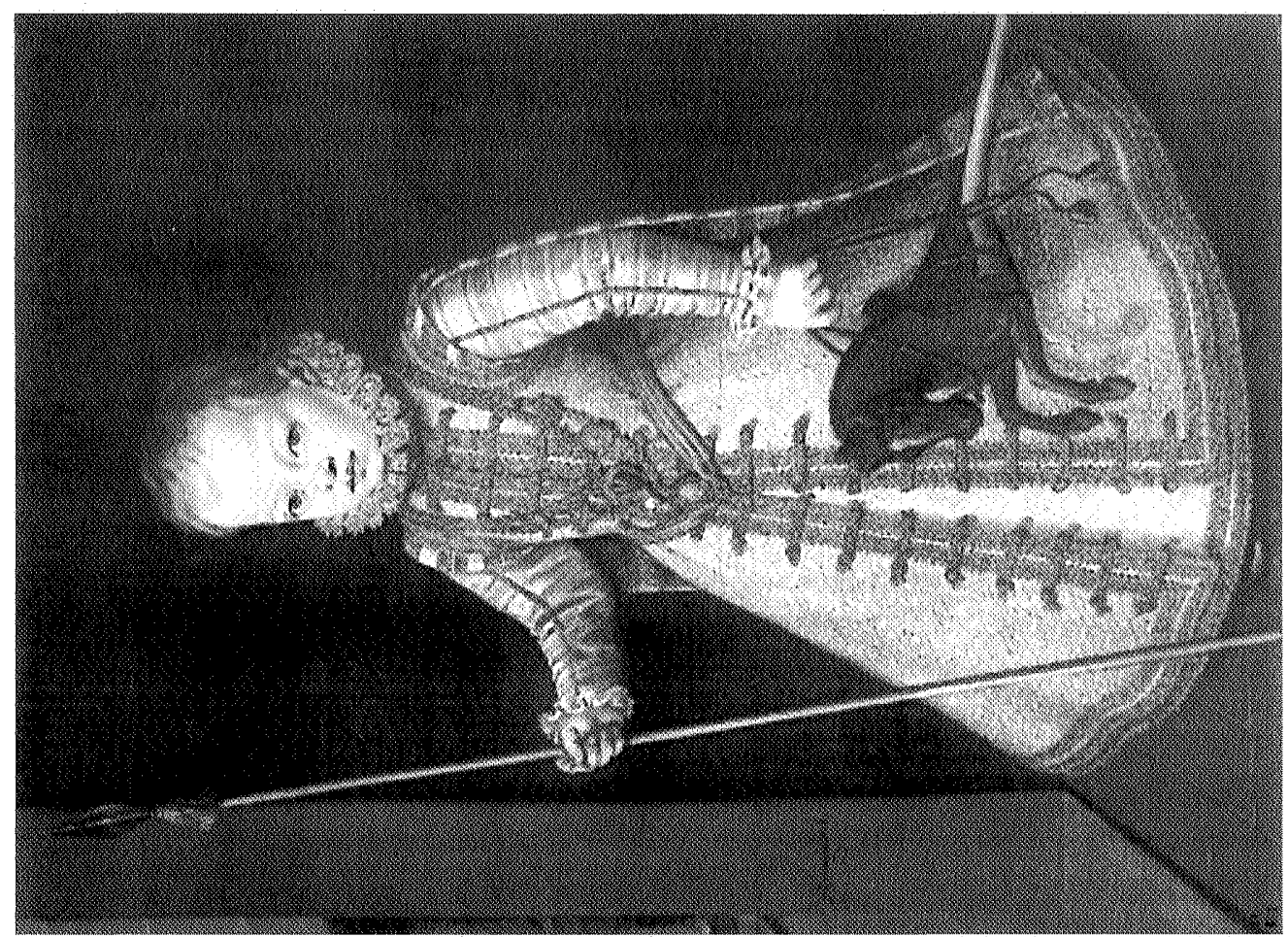

$\frac{8}{8}$

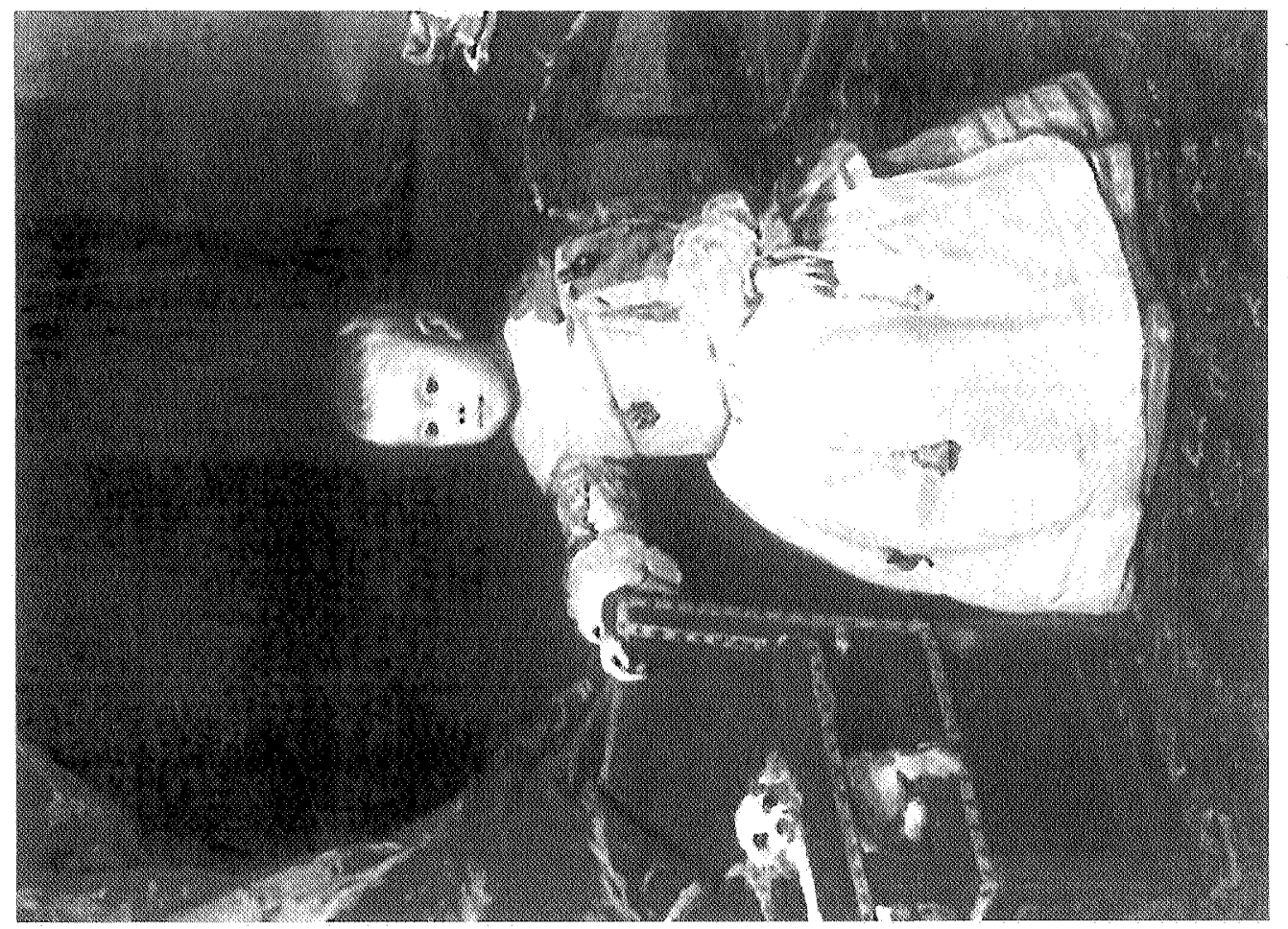

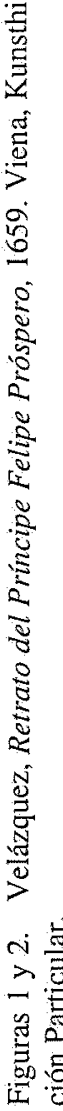


ser cardiaca, además, curiosamente, Felipe II, tenía una «piedra de color, de cornerina, a manera de corazón, con un cordón de seda encarnada y plata, que dicen es buena para mal de corazón; que pesa con su cordón trece castellanos: Tasada en dos ducados» ${ }^{15}$. Entre las propiedades que tenía la cornerina, que también era de color rojo, no estaban las relacionadas con el corazón, por lo que es posible que la «virtud» de esta piedra del Rey estuviese en su forma, no en ella misma. De todas las maneras, su posesión regia nos refuerza la idea de su uso con fines mágicos por la Familia Real.

Felipe II también había sufrido por la descendencia masculina, motivo que le había impulsado a contraer cuatro matrimonios, de los que sólo sobrevivió, para su tranquilidad, además de sus dos hijas, Isabel Clara Eugenia y Catalina Micaela, el ansiado heredero y futuro Felipe III. Este, que sin duda compartió las angustias de su padre, decidió «proteger» a sus hijos desde su nacimiento, pues de sus ocho hijos, han llegado hasta nosotros retratos de cinco de ellos usando amuletos y talismanes. Inexplicablemente, Tormo, piensa que esta costumbre se inicia en España justo en este momento, de la mano de la Reina Margarita de Austria ${ }^{16}$, otros autores, como Cortés, se lo discuten, apoyándose en que sólo aparecen en los retratos de Infantes lactantes ${ }^{17}$, obviando el citado retrato del pequeño Diego Félix.

La Infanta Ana Mauricia, nacida en 1601, y que llegó a ser Reina de Francia, es decir, que escapó a la «maldición», en la pintura de Pantoja de la Cruz, de 1602, conservada en las Descalzas Reales, Madrid, (Fig. 3), se nos muestra materialmente cubierta de ellos, sobresaliendo los ya continuamente mencionados: La higa de azabache, la campanilla, en este caso una magnífica pieza de oro trabajado con relieves esmaltados, una rama de coral y un cuerno. Este último talismán es nuevo, ya que no aparecía en los retratos que hemos visto, pero su uso también estaba muy extendido, servían de silbatos, por lo que se relacionaban estrechamente con las propiedades atribuidas a las campanillas: También su sonido ahuyentaba malos espíritus y brujas.

Su hermana María, nacida en 1606 y futura esposa de Fernando III de Alemania, en su retrato por Pantoja de la Cruz, de 1607, (Kunsthistorisches Museum, Viena), (Fig. 4), lleva también unos cuantos, en este caso, dos higas, una de azabache, distinta ya que tiene los dedos extendidos, y otra de coral, la campanilla, de oro engastada con rubíes tablas en monturas cuadradas, y el cuerno, y lo mismo sucede en el retrato de la Infanta Margarita Francisca, nacida en 1610, posiblemente obra de Bartolomé González, de 1611-1612, en el Museo del Prado ${ }^{18}$, aunque en este caso, ni la higa de azabache, ni la campanilla, ni el cuerno,sirvieron de mucho, puesto que la niña falleció en 1617.

Aún hay dos retratos más, uno de ellos del Infante D. Fernando, de año y medio, por lo tanto presumiblemente de 1610, atribuído con dudas a Bartolomé González, propiedad, en 1925, del Marqués de Valverde de la Sierra ${ }^{19}$, en él aparecen hasta seis relicarios y amuletos, amén de la campanita dorada. La otra pintura, es un retrato triple, el de los Infantes Fernando, Alonso o Alfonso Mauricio, nacido en 1611 y fallecido un año después, y Margarita, de mano de Bartolomé González, pintado en 1612, (Kunsthistorisches Museum, Viena). En

15 Sánchez Cantón, Francisco Javier: Archivo Documental Español. Inventarios Reales: Bienes Muebles que pertenecieron a Felipe II. Madrid, Real Academia de la Historia, 1956/1959, p. 271, n. ${ }^{\circ} 2148$.

${ }_{16}$ Tormo, Elías: En las Descalzas Reales de Madrid. Madrid, Blass S.A., 1944, Vol. II, p. 100.

17 Cortes Echanove, Luis: Nacimiento y crianza de las personas reales en la Corte de España. 1.5661886.Madrid, C.S.I.C., 1958, pp. 33-34.

18 Ibidem, p. 31, nota 2 y lám. IV.

19 Exposición de retratos de niño en España. Madrid, Sociedad Española de Amigos del Arte, 1925, p. 12, n. $^{\circ} 6$. 
él, es precisamente el Infante que falleció en ese mismo año, Alonso o Alfonso, apodado «El Caro», ya que su parto le costó a su madre la vida, quien, como lactante, dando en parte la razón a Cortés, aparece «protegido» por varios amuletos y talismanes entre los que destaca la higa de azabache y el cuerno.

Todas estas higas, campanillas y cuernos, ¿son los mismos?, no. Aunque en muchos casos se heredaban, como comentaremos a continuación, el simple análisis visual de todos ellos en los diferentes retratos dejan bien claro que se trata de objetos distintos, aunque eso sí, extremadamente similares.

Los amuletos y talismanes del Príncipe Felipe Próspero, están documentados por D. Jesús, quien nos informa que probablemente habían pertenecido al Infante D.Fernando, nacido poco después y fallecido a los siete u ocho meses, pues a su muerte, en 1659, tenía entre otros, «una higa de azabache, con engaste, cordón, as a y reasa de oro esmaltada de transflor... una campanilla de oro...y una higa guarnecida de oro...» y que es posible que éste los heredase a su vez del Príncipe Baltasar Carlos. Cuando en 1661 muere Felipe Próspero, se sabe que tenía «una higa de azabache con diamantes en el tope y en los dedos... campanilla de oro... una higa de coral con su cadenilla... y una higa de azabache guarnecida la muñeca de diamantes...», y que Felipe IV, ordenó que pasasen todos sus dijes al nuevo hijo por nacer, que fue el Príncipe Carlos, el famoso Hechizado, aunque para éste Juan de Villaroel, platero de su Majestad, hizo otros nuevos similares, como «una campanilla de oro tallada y esmaltada... dos higas, una de cristal y otra de azabache; y un coral engastado en oro ${ }^{20}$.

Hasta ahora, el seguimiento que hemos hecho de todos estos amuletos y talismanes ha sido a través de la imagen pintada y los documentos, pero...¿¿Se conserva algún ejemplar? Sí, aunque por desgracia ninguno de ellos pueda ser identificado con los que veniốnos estudiando. De todos ellos, la higa era sin duda la «reina», ya que he podido localizar diecinueve, todas ellas consideradas trabajo español, datadas desde mediados/fines del siglo XVI a comienzos del XVII. Nueve son de cristal, tres de marfil, dos de coral, otras dos de madera, una de azabache, una de oro y otra de ámbar. Llama la atención, la gran cantidad de ellas que son de cristal, pero esto no ha de extrañarnos, ya que sobre él, encontramos que «dizen tener virtud contra el mal de ojo» ${ }^{21}$, lo que confirma su uso con fines mágicos, además, acabamos de citar una higa de cristal, entre las pertenencias de quien se convertiría en el Rey Carlos II.

Por lo anteriormente expuesto, creo interesante comentar varios ejemplares. Empezaré por una de las de madera, considerada un ex-voto de Carlos I ${ }^{22}$, engastada en una montura a manera de puño de manga, de plata dorada y esmaltada, que se conserva en la Catedral de Gerona, (Fig. 5). Es algo diferente al modelo que hemos expuesto, ya que no presenta el puño cerrado, sino que está abierta, con los dedos pulgar e índice unidos formando un anillo, presentando la peculiaridad de llevar en el dedo índice una sortija de oro engastada con una perla.

Poco sin embargo, es lo que puedo decirles sobre la higas de azabache y coral, puesto que carezco de su imagen fotográfica, de la de azabache, sé que estaba montada en plata dorada y que formó parte de la colección de un pionero del estudio de la joyería española, el Baron Charles Davillier, y que ahora está en una colección privada ${ }^{23}$. Las de coral, ambas en

20 Hernández Perera, Jesús : Op. Cit., pp. 282-286.

21 Arfe y Villafañe, Juan: Op. cit., p. 61 .

22 Tait, Hugh: Jewellery through 7000 years. Londres, British Museum Publications Limited, 1976, p. 225 , n. ${ }^{\circ} 374$ y Carlos $V$ y su ambiente. Catálogo de la exposición celebrada con motivo del IV centenario de su muerte, (1558-1958), en el Hospital de Santa Cruz de Toledo. Madrid, Estades Gráficas, 1958, p. 304, n. ${ }^{\circ} 925$ bis, lám. CCXIV. 
el Instituto Valencia de Don Juan, en Madrid, han sido catalogadas por mí con muchas lagunas, ya que sólo se me dejó ver sus fotos, en blanco y negro, en dicha Institución. Una de ellas, la más rica, tiene una montura en forma de puño de una manga, en oro con labor de filigrana, esmaltado y engastado con piedras cuadradas tablas en monturas piramidales. La otra, aunque también tiene una montura semejante de oro esmaltado, carece de piedras preciosas $^{24}$.

Algo similar me ocurre con las de cristal, sólo de una de ellas puedo ofrecerles la imagen, por esa razón ha sido la elegida, se conserva en el Museo Lázaro Galdeano de Madrid, (Fig. 6), está montada en un puño de manga con su lechugilla, en oro labrado con cartelas recortadas y esmaltadas de azul, blanco y verde, con ¿rubíes? redondos cabujones engastados en monturas cupulares, en el ápice, la doble anilla movible para la suspensión ${ }^{25}$.

Pero, además de los ejemplares de higas citados, los que hemos podido ver en los retratos y leído en los documentos, tengo que advertirles que en la joyería de los siglos XVI y XVII, se realizaban dibujos y grabados de joyas, destinados a los talleres de los orfebres. Así, se conserva en Barcelona, en los «Llibres de Passantíes» del Museo de Historia de la Ciudad, (Fig. 7 ), un dibujo para un colgante en forma de higa, sosteniendo una flor con los dedos pulgar e índice, con su lechugilla y puño decorado con cartelas, es la prueba de maestría que el oficial de orfebrería Perot Estirivill realizó, junto con otras pruebas, el día trece de Diciembre de 1586, con el fin de alcanzar el título de maestro y poder abrir su propio taller ${ }^{26}$.

De las campanillas de oro, he localizado un ejemplar, con toda probabilidad español, de fines del siglo XVI, en el Instituto Valencia de Don Juan, Madrid, con los mismos problemas ya citados. Se trata de un colgante en oro esmaltado siguiendo un diseño de motivos vegetales, con una anilla fija en el ápice, por la que pasa unos eslabones de cadena rematados por otra anilla para la suspensión ${ }^{27}$.

También he conseguido localizar una joya en forma de corazón, similar y distinta de la que hemos hablado, similar porque se trata de un colgante de oro en forma de corazón, distinta porque está engastado con una malaquita, es trabajo alemán del primer tercio del siglo XVI, conservado en el Bayerisches Nationalmuseum de $\mathrm{Mu}$ nich. Curiosamente fue encontrado en la tumba de una niña, la Condesa Palatina María Magdalena, (1628-1629), hija de los Condes Palatinos Johann Fiedrich y Sofía Agnes Von Hesse-Darmstadt ${ }^{28}$.

Finalmente, se conserva un colgante cuerno, trabajo del sur de Alemania, de alrededor de 1600, en el Kunsthistorisches Museum de Viena, (Fig. 8). Cumple la función ya señalada de silbato, y está montado en oro esmaltado de blanco y azul, engarzado con rubíes y esmeraldas cuadradas tablas en monturas piramidales ${ }^{29}$.

23. Robinson, J. C. : Op. cit., p. 73, n. $^{\circ} 301$.

24 Horcajo Palomero, Natalia: Joyería Europea del siglo XVI. Estudio tipológico y temático. Madrid, Editorial de la Universidad Complutense, 1992, Tomo I, p. 365, n. ${ }^{\circ} 570$ y pp. 365-366, n. 571.

${ }_{25}$ Muller, Priscilla E.: Jewels in Spain. 1500-1800. Nueva York, The Hispanic Society of America, 1972, p. 69 , Fig. 94

26 «Llibres de Passantíes». Barcelona, Museo de Historia de la Ciudad, Llibre II, folio 289.

27 Horcajo Palomero, Natalia: Joyería Europea... tomo I, p. 462, n. $^{\circ} 734$.

28 Samers Coks et alii: Princely magnificence. Court jewels of the Renaissance. 1500-1630. Londres, Debretts Peerage Limited in Association with the Victoria \& Albert Museum, 1980, p. 75, n. 75 y foto p. 73.

29 Ibidem, p. 75, n. $^{\circ} 77$ y foto p. 68. 

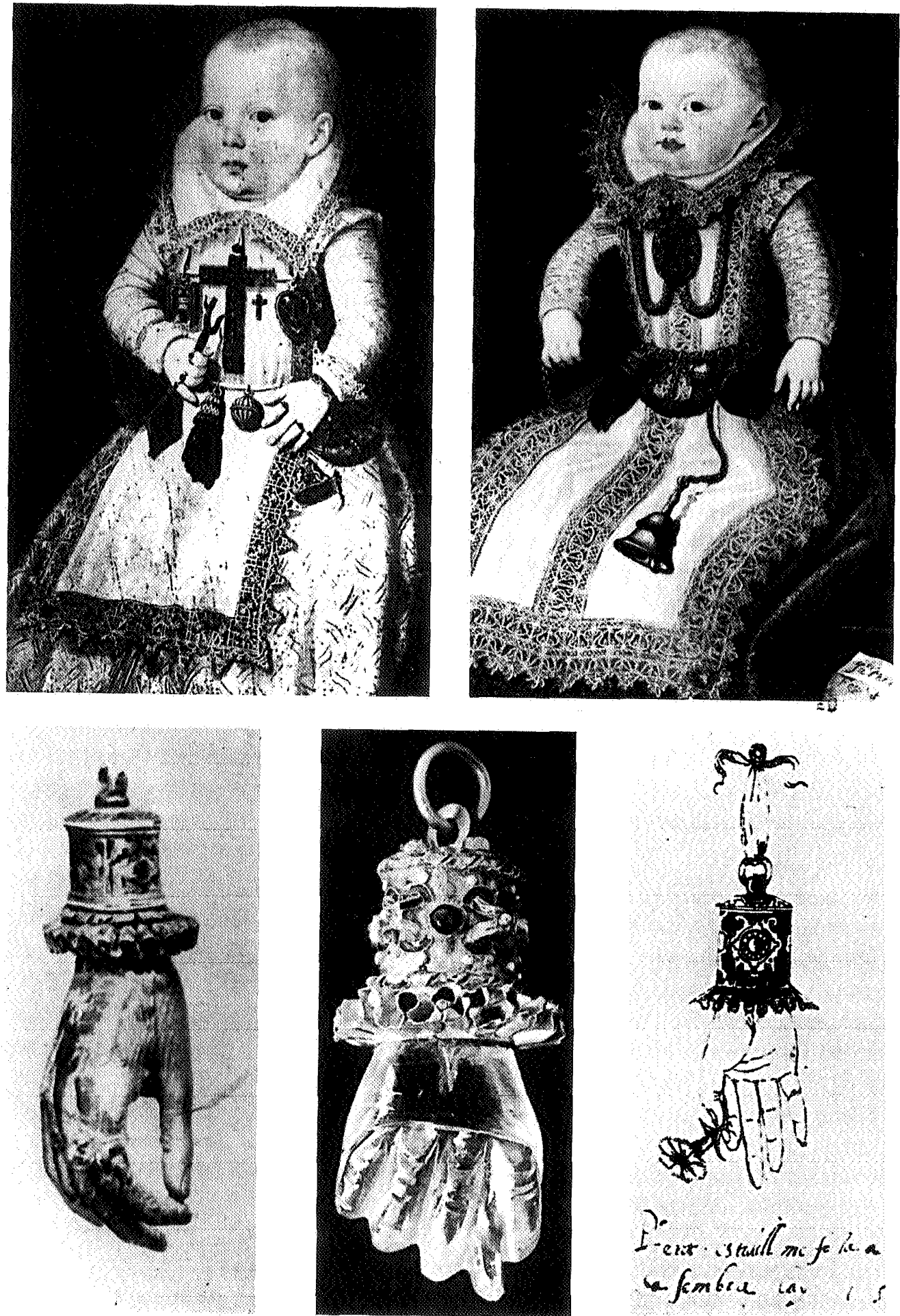

Figuras 3-7. Pantoja de la Cruz, Retrato de la Infanta Ana Mauricia, 1602. Madrid, Descalzas Reales. Pantoja de la Cruz, Retrato de la Infanta María, 1607. Viena, Kunsthistorisches Museum. España, segunda mitad del siglo XVI. Colgante en forma de HIGA, oro, plara dorada y esmaltada, madera y una perla, Gerona, Catedral. España, segunda mitad del siglo XVI. Colgante en forma de HIGA, oro esmaltado, cristal de roca y ¿rubíes?, Madrid, Museo Lázaro Galdeano. Perot Estirivill, Dibujo para un colgante en forma de HIGA, Barcelona (Cataluña, España), 13 de Diciembre de 1586. Llíbre II, Folio 289. Barcelona, Museo de Historia de la Ciudad. 

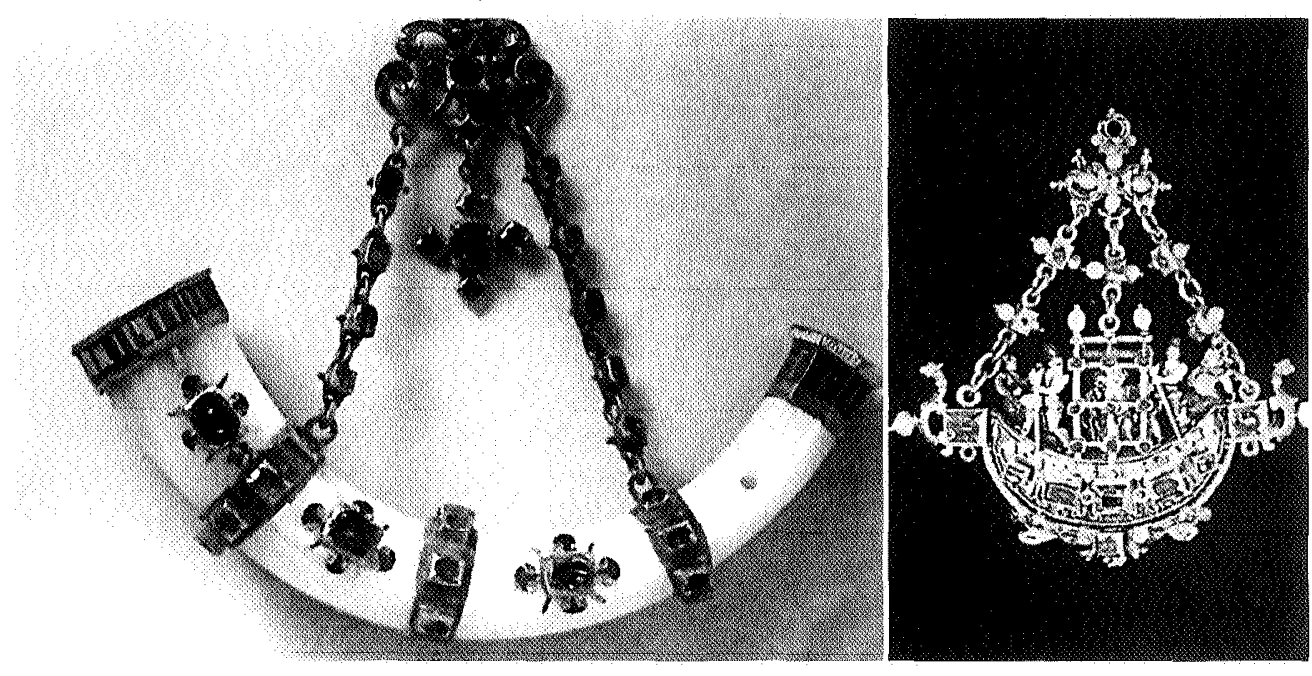

Figuras 8 y 9. Colgante-CUERNO/Silbato, oro esmaltado, rubíes y esmeraldas. Alemania (Sur), h. 1600. Viena, Kunsthistorisches Museum. Colgante BARCO, oro esmaltado, rubíes, esmeraldas y perlas, ¿Italia?, segunda mitad del siglo XVI. Florencia, Museo Degli Argenti, Palazzo Pitti.

No querría sin embargo terminar este estudio, sin hacer alusión a un colgante que D. Jesús cita entre las pertenencias del Príncipe Felipe Próspero, se trata de «una gondolilla pequeña de plata con seis remeros» ${ }^{30}$, ya que los colgantes-barcos, galeones, carabelas, góndolas... eran muy utilizados en el Renacimiento, llegando cuarenta ejemplares hasta nuestros días, aunque eso sí, todos de oro con esmaltes y piedras preciosas. Hay muchas dudas sobre cual sea el país de origen de este tipo de colgantes, pero Italia es quien tiene más ejemplares adjudicados (Fig. 9). Para Hackenbroch posiblemente eran ex-votos ofrecidos a un santo en agradecimiento por la feliz travesía en un barco de su donante, mientras que para Tervarent, eran un símbolo de la esperanza ${ }^{31}$, esperanza que era precisamente la que tenían que tener puesta los Reyes en la vida de sus hijos, y que tal vez nos explique la presencia de un colgante de este tipo entre los amuletos y talismanes principescos.

Y esto es todo lo que puedo, hasta el momento, contarles sobre ciertos curiosos aspectos del retrato de un pequeño Príncipe, Felipe Próspero, realizado por un gran pintor, Diego Rodríguez de Silva y Velázquez, partiendo de un interesante trabajo, como lo es el del profesor Hernández Perera.

${ }^{30}$ Hernández Perera, Jesús: Op. cit.. pp. 284-285.

${ }^{31}$ Hackenboch, Yvonne: Op. cit., pp. 50-52 y Tervarent, Guy de: Attributs et symboles dans L'Art profane. I450 -1600. Ginebra, Librairie E. Droz, 1958-1964, pp. 282 -283. 